mote their growth, and the growth of natural knowledge throughout the world.

Prof. Stokes said :- Scientific men know well how fascinating is the pursuit of science. Some have even gone so far as to consider that it would be polluted, if I may so speak, by being applied practically. An eminent foreign mathematician delighted in the theory of numbers because one could not conceive that it could have any practical application. An eminent English mathematician $l$ heard express a somewhat similar sentiment. All honour be to those who are so immersed, if I may so speak, in abstract science, that they disregard and even dislike its application. They pursue science with all the more zest, they pursue it in directions which possibly otherwise might not have been followed out, and possibly in the end their own investigations may admit of applications which they never dreamt of, But for my own part my tastes do not quite lie in that direction. I like to see science connected with applications thereof, no matter to what purpose. Now, when we apply abstract science to physical subjects, we are not only enabled to investigate natural phenomena in a manner which could not otherwise be done, but the study reacts on the most abstract parts of science, and enables us sometimes to see, as if it were by intuition, truths of an abstract nature, such as, for example, propositions in pure mathematics, which we perhaps should never have arrived at if we had not viewed them through the spectacles, so to speak, of their physical application. But this is not all. When science comes to be applied to the wants of life, scientific men are placed by the practical man in the condition of making experiments which oftentimes would otherwise be impossible. When science comes to be applied to commercial purposes, it then becomes possible to construct instruments on a scale the expensiveness of which would have been utterly prohibitory to the purely scientific man. But when these instruments are constructed, it may be, for commercial purposes, the scientific man on his part is able by the favour of those who have constructed them, or of those for whom they have been constructed, to make experiments with them which oftentimes are of great interest from a purely scientific point of view.

Dr. Gladstone, responding on behalf of the "Royal Institution, said :-At the Institution there were not merely memories binding them to all those who had passed away, but they had also many relics. They preserved the log-books of Davy, Faraday, and others, and not only that, but there a great number of pieces of wire, sealing-wax, and card, all damaged, and many other things which Faraday especially used to delight to work with and to carry out in the first experiments which were suggested by the ideas that were working in his brain, and these were preserved as germs of some of their great discoveries. And here he wanted to point out one of those germs connected with telegraphy. Those relics preserved at the Royal Institution were only worth originally a few pence or shillings. How different the monster wealth which had now become the capital of those great enterprises! As far as the Royal Institution was concerned, its connexion with the electric telegraph was to a certain extent not direct, and yet it was very real. Sir Humphry Davy worked there of course largely on galvanic electricity, but he belonged to the pre-telegraphic era. Faraday himself commenced to work early on these matters, and continued to try and image in his own mind what was taking place in these phenomena. It was an important point with him that the glories of science should conduce to the benefit of man. They knew his influence with Sir Charles Wheatstone was very great, and he got him into the dark chambers at the Royal Institution and talked to him about his investigations, and in the theatre brought before him some of those experiments which were afterwards performed with so nuch success in public. In one way and another Faraday had to do with the industrial applications of electricity, as well as with scientific discovery. They had the combination of the purely scientific man with the practical man, and then the two going together with slow, careful, conscientious investigation, followed by the energetic carrying out of the discovery in a form which benefited mankind.

Mr. Shaw-Lefevre, M.P., in proposing the " Societies representing Applied Science," said :- -When I was a boy, at Eton, I recollect well the extension of the telegraph from London to Slough, and an incident of which you are all aware, the arrest of Tawell, which I believe brought the telegraph more into notice than anything else at that time. It might have been expected that the authorities of Eton, seeing a great invention of this kind brought to their door, might have been desirous of explaining it to the boys of the school, and might have been drawn out of their deep slumber of ages and done something for the scientific education of the boys then at Eton. But no thought of the kind ever entered into their minds, and the only notice taken of it at the time was that they set it as the subject for Greek verses. I and all the boys of my class commenced racking our brains to write some Greek iambics upon a subject of which we knew nothing, and to bring it into connexion with the mythology of the ancients, of which we knew a good deal. I refer to this for the purpose of showing you how little scienee was promoted then at our public schools. I am glad to say that things have been changed since then, but much has to be done in this direction, and there cannot be a doubt that if this country is to hold its own in the great industrial competition it must give a greater place to science in our schools, and equalize the endowments between the classical and scientific studies; and it is only by doing that I am persuaded that we can hold our own. Mr. Bruce, President of the Institute of Civil Engineers, and Mr. Latimer Clark, past President of the Society of 'Telegraph Engineers, replied; and the latter, after alluding to the work done by the brothers Brett in submarine telegraphy, said :I feel that we, as the representatives of applied science, have been somewhat neglected by the world. I feel that the politicians, some of whom have honoured us by coming here this evening, have very much neglected us. I don't allude to honours, for we shall be very well content with the position of things in that regard; but $I$ feel that they have robbed us of much of our credit for the fact that the great effects of the jubilee which we are now assembled to commemorate have been due to the agency of the applied sciences. I do feel that politicians have been permitted to claim for themselves the credit for the wondrous benefits civilization has received from the efforts of applied science. We hear that so many shillings have been taken off a quarter of wheat, we hear that all the prosperity of the country has been due to free trade, but I say it is not so; I say they have robbed us of our honours in saying that ; I say as guild and craft we ought to proclaim loudly to the world that to our efforts most of all the prosperity of the last fifty years has been due. The population of this great city and of this country when it eats its breakfast to-morrow morning will be consuming food a very large proportion of which has been brought to this country by means of applied science. It is that which has given us our prosperity. They have not taken 5 s. or Ios. a quarter off wheat and corn and eatables, but they have taken off 60 s., 80 s, and Ioos. Wheat will be brought to-morrow from places from which it could not have been brought fifty years ago for ten times what it now costs. As a guild and craft we ought to proclaim loudly that the benefits which we have conferred are the real cause of the prosperity of the great Victorian era which we meet here to celebrate.

The Earl of Onslow having proposed the health of the Chairman in a suitable address, and the Chairman having responded, the proceedings terminated.

The Postmaster-General, during the evening, despatched the following telegram to Sir Henry Ponsonby, at Osborne :--"A large dinner-party celebrating the jubilee of the electric telegraph, remember with gratitude and pride that all the progress has taken place in the happy and proiperous reign of $\mathrm{Her}$ Majesty and under her fostering care."

To this the following reply was received:- "The Queen thanks you for your telegram. It gives Her Majesty much pleasure to reflect on the improvements which have been made in Wheatstone's great invention, which was first practically tested in her reign."

\section{THE CASE FOR A LONDON TEACHING UNIVERSITY.}

THE questions connected with the proposal for the establish. ment of a Teaching University in London were discussed in a speech delivered by Sir George Young at the distribution of prizes in the Medical Faculty of University College, London, on June I, and in a speech delivered by Dr. J. E. Erichsen at the distribution of prizes in the Faculties of Arts and Laws and of Science, at the same institution on June 30. As the case for a London Teaching University was stated by these two eminent authorities, we reprint part of what they had to say on the subject from the point of view of University and King's Colleges. 
I.

Having referred to the drawbacks connected with "the system of separation between institution and institution concerning University matters" in London, Sir George Young went on to say :-

I will touch upon some of these drawbacks-drawbacks which, as I have said, I do not impute as matters of fault to any man or to any set of men, but to the mischiefs of the system; and I will draw my instances (and you are to consider that I could give you many others), as in duty bound upon this occasion, from the medical side of the question.

Well, gentlemen, in the first place we are brought face to face with a very serious and very unpleas znt condition of things in the fact that several of our students, we find, are in the habit of leaving us from time to time in order to finish their course of study at other institutions where degrees are conferred, in orcier to qualify for those degrees. We have always been, as Broke said of the Shannon, "an unassuming ship," and I am not going to boast. Let us admit that there may be elsewhere teachers as eminent as those I see around me. Let us admit that there may be elsewhere possibilities of study comparable to those which are to be obtained in this place. But I will not admit-it is my duty to deny, and the point is conceded by others outside our limits - that there is anywhere a more eminent body of professors and instructors than that which has now, for two generations, led the van in matters of medical instruction of a university kind in this College. I will not admit that there is anywhere, in any part of the world, a field of study presenting greater opportunities to the student than that of London with its numerous medical schools, and with its numerous facilities for scientific study.

Next let me mention an evil, for which the University of Lnndon is not responsible--for which nothing, indeed, can be said to be responsible except the non-existence of that university which the University of London is not. Not only are medical schools, as we know well, dependent upon hospitals, but also, what is not so generally known to the public, ho pitals are dependent for their ad ninistration upon medical schools. As London has spread and as one generäl hospital after another has been founded, each has attached to itself its own separate medical school. Each school must provide, in order to satisfy professional requirements, not merely that clinical teaching for the sake of which it is founded, but also scientific teaching of a multifarious and expensive character. In some of these schools, as is well known, it has been found impossible to provide this scientific teaching in a manner sufficiently effective for the purposes of the school. There need be no delicacy, gentlemen, in mentioning this, because, in fact, it has been most honourably acknowledged by several of these medical schools in their recent action. It was lately brought to our notice that in the case of several of them, they have practically, in some branches, given up the scientific training of their students, and have entered into an arrangement with the Government school at Kensington, by which their students should there receive that teaching which they found themselves unable to give. Well, gentlemen, at the Council of this College we had something to say-we had some objection to take-to that arrangement. With that I need not trouble you further than to say that we thought a Government department ought not to lend itself to an exclusive arrangement of this kind. We thought that it would have been better for the students themselves and for the public if the matter had been left open whether they should go to South Kensington for their chemistry and physiology, or come, if they so preferred it, to ourselves. But at the same time, gentlemen, you must not consider me in this matter to be impeaching the conduct of the other schoo's. As men of the world, we are quite aware that medical schools are to a certain extent rivals, and we cannot expect, merely because we asked it, that the natural jealousies of rivals should be allayed, and that a medical school in so delicate a matter should freely accept our offers of instruction for its students who, they might suppose, would perhaps be detached from their affection for their own school by frequenting this place. Well, gentlemen, what is the remedy that we should look to? I think that you will agree that we ought not, as a Council, to sit down and seek no remedy for such a state of things as this. Why, surely the remedy is that some central authority should be provided---some institution where we can meet our sister schools upon equal terms, not that wholesome emulations should be extinguished, but that the mischiefs which arise from their excess should be obviated, where, in fact, teachers and administrators might meet together for the purpose of arranging for improvements in medical education upon a common footing and without fear of mutual injury.

This, among other instances of the same kind, many of which I could give you, led some of us, as much as three years ago, into a long inquiry into the matter, and eventually into a movement for the foundation of a Teaching University in and for London. The year before last, at the meeting of the sister Faculties, the Dean of the Faculty of Science, Prof. Graham (whom, I hope, we shall see before long among us restored to health), called our attention to the movement and expressed his sympathy with it on the part of the Faculty. The President of the College, Lord Kimberley, expressed also his warm sympathy with the movement, and said (I am quoting his words, which will be found in the Report of the College of that date) :"There is nothing more dissati-fying to the minds of students and of educational men, than that in this great city there should not be some more complete establishment of some universal system. We may not see it accomplished. I do not suppose that anyone sees at present how the end is to be attained, but I am quite certain that it would be for the benefit of all the institutions of this great city that they should be gathered together and the teachers and managers brought into a close and immediate contact." With that encouragement we, many of us, took up the movement warmly, and it has now been brought to the practical stage of definite proposals and of a formal programme. We ask, in short, that the same privilege which has already been conceded to country colleges through the Victoria University shall be conceded also to us in London. Gentlemen, we cannot go to Manchester. We cannot s3 far ignore our position and our history as to seek for admittance from the offipring of our offspring. Besides, we ought not to be compelled to go to Manchester. The system of the Victoria University, as I have inclicated, is that of an imperfect university, arising from its being scattered over several cities at great distances from each other. There is within our reach the more complete system of a localized university; for who will have the face to say that in this great population of something like four millions residing within limits admitting of daily intercourse there is not material enough - there is not ground enough-to support a local teaching university of its own?

There were working with us for a long time, in the course of this inquiry, several active members of the Convocation of the University who had themselves been interested in similar movements, and who desired to see the development of that University in the direction to which our hopes and wishes also pointed. By their exertions, and as a consequence of our movement, the Convocation and the Senate of the University of London have been brought separately to consider this matter, and have put forward from time to time certain proposals for what I must call a compromise. Those proposals have been officially communicated to us through our President, and have been, I need not say, carefully considered by the Council. They do not amount to that which we desire. They did not cover that which we claim. They are limited to this: in the first place, that there should be introduced in the Senate of the London University eight representatives of the four Faculties of the Universitytwo to each - such representatives to be chosen by assemblies of the Faculties, and the assemblies of the Faculties to consist of representatives of the institutions throughout England which send up candidates to the University. There is also a provision for Boards of Studies to be constituted out of these same Facul. ties to exercise purely consultative and deliberative functions. I think that is all-all, that is to say, of a practical character. There is no doubt-and it is an important matter considered from the point of view of our argument-a proposal that in the preamble, in the objects of the University, there should be included a statement, that its purpose is to encourage education, especially in London; and there is also a proposal that as time and opportunity are given, it shall have power to found Professorships, provided that such Professorships shall not compete unfairly with our own. But, passing over these two latter proposals as not exactly of a practical character, I say that the proposal to admit eight gentlemen, representatives of assemblies the constitution of which is not very clear to me, upon the Serate of the University, and to appoint these Boards of Studies composed of representatives so gathered from all parts of England, is not what we want. It does not meet our views; and for several reasons.

In the first place, the representation which would be given to this College on such a system in the governing body of the 
University, if it is to be a teaching university and not merely an examining one, is entirely insufficient. In the next place, the Boards of Studies, the Faculties, and the new members of the governing body, would represent, not London, but all England, and therefore would constitute an organization entirely differen from that effective organization which we contemplate, which is to meet often, to take count of teaching-matters in London, and to do a great deal of work in the development of University education in this place. We therefore are obliged to reject these proposals, and to proceed, without any feelings of hostility and without any bitter words towards the University of London, to ask for that which we consider necessary for the effective carrying on of our own work.

Let us keep clearly before us what a teaching university really is. We need not go farther than this institution to see it, provided only that were added to us which we want-the power to confer degrees. It has not merely to provide for-it has to commend to its students the best possible teaching under the best teachers obtainable in all the subjects of the University. A university which by its very constitution is indifferent to methods of teaching and does not care how a man has obtained his knowledge, cannot be said to commend to its students any particular methods or ways of obtaining that knowledge. It rather has a contrary effect. Under these circumstances it is useless to try to set up an institution which shall combine a mixture of two principles-the principle which considers degrees merely as the marks of a liberal education, tested, no doubt, by an examination, but covering very much more than the mere showing of knowledge in examination, and the other, the rival system, which, giving up the testing of methods of educationgiving up the marking of a regular education as beyond its scope -confines itself to the setting of a mark upon performance in the answering of examination-papers.

No, gentlemen, if the University of London were to move in this direction, it would spoil its own thoroughly good and honest work without doing ours. There will still remain when we have obtained this Charter, plenty of candidates for its degreesplenty of work for it to do-plenty of honour to those who obtain them. But surely there is room for us by the side of it. There is room for an institution which shall comprise not merely this College, but King's College and the Medical Schools of Loncion, and which, organizing them together as a Teaching University, shall give us that which we want for the efficiency of our work-an institution in which the teaching which we give is duly honoured-is not placed in an inferior position beside the teaching which is given by other universities and in other university colleges.

We ask, therefore, that a Charter to confer degrees upon all persons who have undergone a regular course of study in a college or medical school of the University and have passed the required examinations, shall be granted to a suitable governing body, upon which the governing bodies of this College and of King's College shall be properly represented, and upon which the teaching staff not merely of this College and of King's College, but also of the other Medical Schools of London, shall have their representatives. In order that the interests of the medical profession may be properly considered-in order that we may not seem to claim that which it is by no means our intention to claim - an unfair position for our own medical schools, we ask an alliance with the Royal College of Physicians and the Royal College of Surgeons, the official representatives of the medical profession in London, in order that by their means that representation may be secured upon the governing body of the University. It is obvious that from their number it would be difficult to represent directly the separate interests of eleven medical schools upon the governing body of a University; but, in so far as the teachers of the various schools have their voiceand that voice, I can assure you, we do not intend should be a small one, in the councils of the University -in so far, we shall consider the teachers of other medical schools entitled to rank on equal terms with our own. ...

There is a movement at present on foot in the College of Physicians for a single-facultied University in London, or an institution in the nature of a University, for conferring medical degrees alone. That movement appears to us to be a part of our movement. By itself, and if the movers insist upon its being considered as essentially a separate movement, we could not look upon it with approval; for we believe that it would be fatal to the prosperity of our medical school. I will put it to you, gentlemen, How would you, the students in this College, regard a state of things under which you were called upon to work for a degree, either at the University of London at Burlington House, or at the Royal College of Physicians? If it were the case, as seems to be indicated, that the degree at Burlington House is to be connected with a very high, a somewhat unusually high, standard, and if the degree which is contemplated by the College of Physicians is to be that creditable average degree which $I$ have indicated as one which, personally, I think ought to be established, do you not see that those medical schools, which like our own, aim at the highest teaching, would have serious difficulties in the matter? Here would be two systems in neither of which we had the least voice, two systems of examining Universities outside us competing for our students and what would our Professors do? They would be called upon, now to train for one system and now for another, and perhaps to keep up double sets of classes, so constituted as to fit the arrangements of two rival bodies.

That is the position in which we should be placed. But if the movement on the part of the Royal College of Physicians (the Royal College of Surgeons joining in it) can be brought into accord with our own, then we shall have already obtained a part of what we seek. I will just mention one reason why I think it most desirable that you, the members of the medical profession, should take this matter seriously into consideration, and should exercise your influence with your colleagues in other institutions, in order that this point may be pressed home to them at the present stage. The visit which it was recently my duty to pay to the Privy Council Office, in order to obtain the forms neces sary for carrying out our own proposals, revealed to me the fact that there exists already in that office a pile of petitions as high as this table against the proposal of the Royal College of Physicians. Now, gentlemen, against our proposals there is no petition and there is no movement. So far as I know, there is no objection in the world.

We do not conceal from ourselves that it is possible opposition may be offered as we go on. That oppositi,n which above all others we should deprecate would be the opposition of the University of London. I have endeavoured to preserve a tone of friendship, such as I sincerely feel, towards that University. I most earnestly deprecate opposition on the part of that distinguished body to the movement which is now on foot for obtaining a University in and for London such as London ought to have. I trust it will not be led into the fatal track of the older Universities, which, by thcir interference, did not prevent, indeed, the foundation of the University of London, but undoubtedly spoiled it, fifty years ago. That such opposition may be apprehended by some of us we cannot ignore in consideration of the very serious matter to which I have lastly to call attention, the resignation, na nely, of our President and of several members of the Council among us. Gentlemen, that these resignations have been to some extent a surprise to us, that they have been a serious cause of anxiety to us, must be obvious; but I think that they have been partly due to a misunderstanding of our aims. I think that the objections which have led to them will, to a large extent, vanish when our proposals come to be more carefully looked into. In the meantime, as for us who remain, we are not disheartened, we are not discouraged. We have at least the satisfaction, such as it is, that the Council of this College is now unanimous in the matter. We have the source of satisfaction which is afforded to us by the unanimous support of the general meeting of the College. We have at our backs the unanimous support of our distinguished body of Professors. We have at our side the unanimous assistance of the great College once our rival, but now our cordial ally. Besides King's College we have friends in every medical school in London, who are corresponding with us and working in the same direction as ourselves. We have friends and well-wishers, I may say further, in every University in England. We have friends in the Press, and we have supporters in the public, and we have received the most encouraging intimations that it will not be long before we are able to fill our depleted ranks in the Council with names which will inspire confidence, and which will materially assist us in carrying our work to a conclusion.

Finally, gentlemen, we have this more than any other as a source of encouragement-that we see our way-that we know the work that has to be done and realize the way in which we hope to effect it. Three years of study and perhaps scores of meetings and conferences have not left us entirely ignorant of the ground. We intend to make this institution greater, more splendid, more efficient, than it has been hitherto, and we expect 
to succeed, because we are labouring not merely for our own aggrandisement, but for the foundation of a University in and for London which will be of incalculable benefit to University education in this mighty centre of population where we live.

II.

Dealing with the objection that a new University cannot be necessary in the capital, since we have already got the University of London, Dr. Erichsen said :-

I wish to speak with the very greatest respect of the University of London, and I entertain the highest respect for the work that has been done in that great institution during the half century that it has been in existence ; and I think that everyone connected with University College must always speak and think of the University of London with that affection with which a parent looks at his child, the University of London being the outcome of University College. We may sometimes look upon it with that feeling of mixed affection and regret with which we contemplate a child that we think has not always been so grateful as it might have been for the fayours received in its early life. But, however that may be, we all speak of the University of London with, and we all feel towards it, the greatest respect and a certain affection.

But the University of London is, in truth, not a university in any sense of the term. The title is misleading and is a misnomer. By a "university" is meant an association of teachers and of students, properly organized, destined for the increase and the transmission of all learning, of knowledge in all its branches, and containing complete Faculties of Arts and Laws, Science and Medicine, and empowered to grant degrees to those of its pupils who are found to be sufficiently qualified for such a distinction. The University of London never has pretended to be a teaching institution, and, so far as its present constitution is concerned, never can be a teaching institution. If it were to become a teaching university it would require to become so completely altered in its constitution as practically to become a new institution. The University of London has only performed one of the functions of a university-that of examining candidates for its degrees. It has performed that function admirably well. The examinations have been carried to a very high standard, so much so that the ordinary pass-examination in some subjects is almost an honours examination. Yet it is only a degree-giving institution, and not a university in the sense in which a university is generally known.

Nor is it "of London" ; for, as was truly said by the Dean of the Faculty of Science in that admirable report that we listened to at the commencement of these proceedings, it is an Imperial University, which draws its candidates from almost every part of the habitable world. It has nothing to do with London except that its head-quarters are situated in Burlington House; but, so far as London is concerned, it might just as well be situated anywhere else. The University of London, then, does not, in any way, supply the want that we wish to fill. With regard to London itself, I may say this, that even as an examining institution the University of London does not supply the desire that has sprung up of late years for academic distinctions. It does not supply the desire amongst the inhabitants of London itself. I can speak of my own profession. Of late years there has been a craving in the medical profession for the possession of degrees. As Sir George Young stated very truly in distributing the prizes in the Medical Faculty about a month ago, if there were no degrees at all we should be none the worse for it; but one may also state something like the converse of that proposition, that if everybody has got a degree nobody is a bit the better for it, and what is common to all can be an honour to none. However, that there exists a great desire for degrees and for academic distinctions there can be no doubt. Well, do the students of the medical schools in London go to the University of London for those degrees? Not at all. They go elsewhere. They go to Edinburgh ; they go to Cambridge; they go to Oxford. At the present moment there are about nineteen hundred medical students at the University of Edinburgh, and nearly seven hundred of them are English. They are attracted there not so much by the superiority of teaching, because-and I say it with all respect to the University of Edinburgh, to which I have reason to be very grateful-the teaching, high as it is, and excellent as it is in all its departments, is not better than the teaching in four or five of the principal medical schools in London; but the students go there simply in order to obtain a degree, because at the end of their studies, instead of coming out as simple Mr. So and-So, they come out as Dr. So-and-So. Well, the others who do not go to Edinburgh, go to Cambridge or go to Oxford; and there is a very large medical school now at Cambridge also, frequented by young men who are desirous of obtaining the degree of that distinguished University. The following incident will show how little the University of London supplies the need for degrees which is felt by London medical men. A few weeks ago there was a vacancy at one of the large hospitals of London for an assistant physician. There were no less than twelve or fourteen candidates. They were all graduates of British universities, and out of this large number of candidates, all London men, educated more or less in London, and practising in London, and attending hospitals in London, there was only one candidate who was a graduate of the University of London. All the others were graduates either of Oxford or of Cambridge. I say, therefore, that men go away from London to get their degrees at the present day. They go to Edinburgh, they go to Cxford, they go to Cambridge, they go elsewhere; but the vast majority do not go to the University of Loudon. That, as a degreegiving institution, does not supply the needs of London itself.

The proposed establishment of this new teaching and degreegiving university has been termed an act of hostility, a kind of declaration of war, against the University of London. Now I can say truly, speaking in the name of my fellow-members of the Council here, that there is no such feeling whatever. No such feeling has animated, I believe, any one of the Council or any person connected with this institution. This proposed university will compete, probably, to a certain extent, with the University of London, but it will compete much more with other universities. It will compete much more with the University of Edinburgh; it will compete much more with the University of Cambridge. There is no direct competition intended with regard to the University of London. There is no reason why a new university should not be established. There is no more reason to complain of competition in the estab lishment of a new university than there is in the establishment of a new school. Every new school competes with every other school in existence. There is no more reason to complain of it than to complain of the introduction of a new member into any of the learned professions. Every man who becomes a lawyer or becomes a doctor may be said to compete with every existing lawyer or doctor. In the same sense the new university, if established, might be said to compete, more or less, with every existing university in the kingdom. In this case there is a competition of friendly rivalry, but nothing else ; and beyond that I cannot admit that there is any special competition with regard to any existing university.

If the University of London does not supply the want felt for higher education, how is that want to be supplied in London? There are only one or two methods. You must either take existing instituiions, or you must create a tertium quid, and what that tertium quid may be I know not. But what existing institutions are we do know, and we do know that there are two institutions in this metropolis which for the last half century have been doing the only work in London that approaches to the higher education, or approaches in any way whatever to university education. They have done that work diligently and well under great difficuities and great disadvantages, but with a fair share of success. I mean this College and King's College. Those are the two institutions; and by the combination of those two institutions we may fairly look for the establishment of a new university in London fully capable of discharging the functions of such an institution.

I happen, from circumstances, to be personally acquainted with, I believe, every university in the kingdom ; and I can say that so far as the equipment of universities is concerned, in the way of museums, laboratories, libraries, lecture-rooms, and all other appliances--what may be termed the "plant" of a university - these two institutions taken singly are equal to most; this one certainly is, and taken in conjunction they are superior to almost all, except the old Universities of Oxford and of Cambridge. I put them aside; but these institutions, University College and King's College, taken in conjunction, are fully equal in all the requirements of a university to the other universities in Great Britain, the Scottish universities and the two universities of this country-one in the north and the other in the midland counties.

I cannot speak with any precision of detail of King's College, but I can speak with precision of this College; and it may be interesting to you to know what this College really is, and what 
it can present to the public in the way of supplying the requirements of a great teaching institution of university rank.

This College, in the first place, has complete Faculties of Arts, Laws, Science, and Medicine, and a School of Fine Arts, as well as a Boys' School. This College has fifty-eight professorial chairs in operation. In addition to the fifty-eight professors, there is a large teaching staft both on the general and on the medical side, - teachers, lecturers, demonstrators, and so on, -bringing up the whole members of the teaching staff to something like one hundred. Last session this College had between nineteen hundred and two thousand students. There were five bundred and fifty boys in the school. The buildings of this College, containing, as I have said, museums, libraries, lecture-halls, laboratories, and all the appliances of a university, are spread over seven acres. They cost $£ 300$,000 in construction. This College holds on trust no less a sum than $£ 200,000$, chiefly devoted to prizes, scholarships, and other objects of that kind; and it holds, besides, in trust a sum of $£ 135,000$ for hospital purposes. Its income is between $£ 33, \infty 00$ and $f 34,000$ a year. Taking, therefore, this College alone, so far as its buildings, the contents of its buildings, and its pecuniary resources are concerned, it stands on an equal footing with several of the universities in Great Britain ; and, taken in conjunction with King's College, it stands undoubtedly superior to some.

To this College, therefore, in combination with King's College, we may fairly look to the attainment of our object of establishing a Teaching University in London which will bring the higher education of London to the doors and within the pecuniary resources of the less wealthy classes of the metropolis, so that the disgrace that has hitherto attached to the metropolis of not affording a higher education, and the discredit that university education in England is to a very great extent a privilege of the wealthier and of the well-to do classes, may be wiped away. It should be within the reach of all, even of the student of the most humble means; and it would be well if this country were to take the example of Scotland in that respect, and to follow it. . .

In this new Teaching University there are two requirements that we insist upon. One is that the candidates for its degrees should have spent a certain specified time in attendance on lectures and instruction within its walls; and the other is that the examinations should be superintended and conducted by the teaching body of the University.

With regard to the first of these two points I wish to say a few words. . There is something more than mere knowledge that is acquired in academic instruction. There is a culture of mind and a development of the moral and social nature that cannot be acquired by solitary study; and it is for these reasons amongst others that those who are in favour of this movement are desirous that the candidates for the degrees of the new University should prosecute a portion, at all events, of their studies within the walls of the institution, so that they may imbibe something of the spirit, and that they may be in some way, too, impregnated by the genizus loci. This has been stigmatized as retrograde; but surely there can be nothing retrograde in that which has been found by universal experience to be the better system of education, and which is adopted in every teaching university in the country.

There is another point, and that is in regard to examinations, and it is a very essential point. We feel, and we feel very strongly indeed, that the examinations should not be directed by an outside body on which there are perhaps no examiners and no teachers, but that the examinations should be conducted by the teachers themselves in the institution in which the candidate learns. I do not say by the individual teacher of each class, but by the general body of the teachers, and that is a very different thing. And, as there would be more Colleges than one in the new Teaching University, a candidate need not in any way be examined by his own teacher, although he would be examined under the direction, superintendence, and control of the general body of the teachers. In every university now, I believe, throughout the Kingdom the teachers are assisted in their examination by assessors or by extra-professorial aid, whenever it is needed, and such, of course, would be the case in the new University. We feel that examinations ought not to lead teaching, and that if examinations are allowed to lead teaching, the teaching is fettered by the examination, and you get to a system of "cram"; the higher education and the higher teaching are apt to be neglected. I recollect many years ago a cir- cumstance illustrating this, occurring in this College in connexion with Prof. Sharpey, one of the mcst distinguished men ever connected with this College, the first Professor of Physiology here and, indeed, in London. There was no course, properly speaking, of Physiology given in London until Prof. Sharpey began his lectures here in the year $1836-37$. Prof. Sharpey gave an elaborate course of Physiology. From the commencement he attracted crowds of students. At that time there was connected with this College a most estimable and most amiable and most excellent old surgeon, who had grown grey within the walls, as it were, of the unreformed College of Surgeons, $\mathrm{Mr}$. Samuel Cooper. $\mathrm{He}$ was an examiner of the College of Surgeons, and I speak of him with the greatest respect; but he was never able to raise his mind beyond the requirements of the examinations of that institution. When he heard of what Prof. Sharpey was doing, he said, "What is the good of Sharpey teaching them all this kind of stuff? We do not want it at the College of Surgeons. We have never asked for it at the College of Surgeons. Why should he teach it to them ?" $\mathrm{He}$ had no conception beyond that, and that is the frame of mind that affects every mere examiner. He has a tendency to fetter and tie down the teaching to the level of his own examinations, and it is impossible to bring him or an examining institution above that level. We therefore wish that the instruction should lead the examination, and that the examination should follow in the wake of the teaching, and not the teaching in the wake of the examination.

\section{SCIENCE AND REVELATION.}

$\mathrm{N}$ the present anniversary, which is the conclusion of my first year of office as President of this Institute, I propose to address a few words to you bearing on the object of the Institute, and on the spirit in which, as I conceive, that object is best carried out.

The highest aim of physical science is, as far as may be possible, to refer observed phenomena to their proximate causes. I by no means say that this is the immediate, or even necessarily the ultimate object of every physical investigation. Sometimes our object is to investigate facts, or to co-ordinate known facts, and endeavour to discover empirical laws. These are useful as far as they go, and may ultimately lead to the formation of theories which in the end so stand the test of what I may call cross-examination by Nature, that we become impressed with the conviction of their truth. Sometimes our object is the determination of numerical constants, with a view, it may be, to the practical application of science to the wants of life.

To illustrate what $\mathrm{I}$ am saying, allow me to refer to a very familiar example. From the earliest ages men must have observed the heavenly bodies. The great bulk of those brilliant points with which at night the sky is spangled when clouds permit of their being seen, retain the same relative positions night after night and year after year. But a few among them are seen to change their places relatively to the rest and to one another. The fact of this change is embodied in the very name, planet, by which these bodies are designated. I shall say nothing here about the establishment of the Copernican system: I shall assume that as known and admitted. The careful observations of astronomers on the apparent places, from time to time, of these wandering bodies among the fixed stars supplied us, in the first instance, with a wide basis of isolated facts. After a vast amount of labour, Kepler at last succeeded in discovering the three famous laws which go by his name. Here, then, we have the second stage; the vast assemblage of isolated facts are coordinated, and embraced in a few simple laws. As yet, however, we cannot say that the idea of causation has entered in. But now Newton arises, and shows that the very same property of matter which causes an apple to fall to the earth, which causes our own bodies to press on the earth on which we stand, suffices to account for those laws which Kepler discovered-nay, more, those laws themselves are only very approximately true; and, when we consider the places of the planets, at times separated by a considerable interval, we are obliged to suppose that the elements of their orbits have slowly undergone slight changes. But the simple law of universal gravitation, combined, of course, with the laws of motion, not only leads to Kepler's laws as a very close approximation to the actual motions, but also accounts for those slight changes which have just been mentioned as

Presidential Address delivered by Prof. Stok P.R.S., at the annual meeting of the Victoria Institute, on Tuesday, July $\mathbf{r}$. 